Document downloaded from:

http://hdl.handle.net/10251/67593

This paper must be cited as:

Samper Madrigal, MD.; Petrucci, R.; Sánchez Nacher, L.; Balart Gimeno, RA.; Kenny, JM. (2015). Effect of silane coupling agents on basalt fiber-epoxidized vegetable oil matrix composite materials analyzed by the single fiber fragmentation technique. Polymer Composites. 36(7):1205-1212. doi:10.1002/pc.23023.

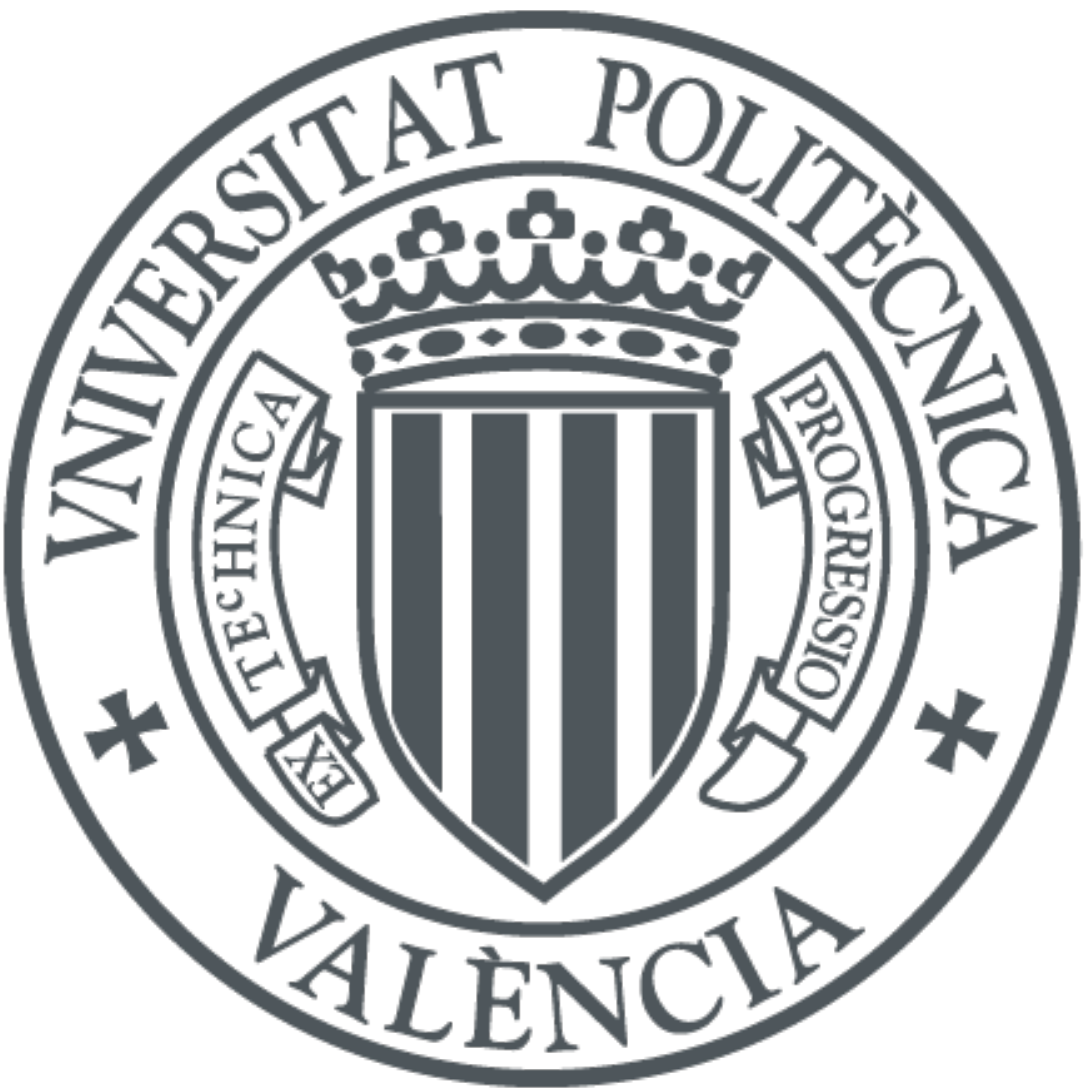

The final publication is available at

http://dx.doi.org/10.1002/pc.23023

Copyright Wiley

Additional Information 


\title{
"Effect of silane coupling agents on basalt fiber-epoxidized vegetable oil (EVO) matrix composite materials analyzed by the single fiber fragmentation technique”
}

\author{
M.D. Samper ${ }^{\text {a }}$, R. Petrucci ${ }^{\mathrm{b}}$, L. Sánchez-Nacher ${ }^{\mathrm{a}}$, R. Balart ${ }^{\mathrm{a}, 1}$, J.M. Kenny ${ }^{\text {b }}$ \\ ${ }^{a}$ Instituto de Tecnología de Materiales (ITM) \\ Universitat Politècnica de València (UPV) \\ Plaza Ferrándiz y Carbonell s/n, 03801, Alcoy, Alicante, Spain \\ ${ }^{b}$ Materials Engineering Center \\ University of Perugia
}

Localita`Pentima Bassa, 21, 05100 Terni, Italy

\begin{abstract}
The fiber-matrix interfacial shear strength (IFSS) of biobased epoxy composites reinforced with basalt fiber was investigated by the fragmentation method. Basalt fibers were modified with four different silanes, (3-aminopropyl)trimethoxysilane, [3-(2aminoethylamino)propyl]-trimethoxysilane, trimethoxy[2-(7-oxabicyclo[4.1.0]hept-3yl)ethyl]silane and (3-glycidyloxypropyl)trimethoxysilane to improve the adhesion between the basalt fiber and the resin. The analysis of the fiber tensile strength results was performed in terms of statistical parameters. The tensile strength of silane-treated
\end{abstract}

\footnotetext{
${ }^{1}$ Corresponding author: Tel.: 9665284 21; Fax: 966528433

E-mail address: rbalart@mcm.upv.es
} 
basalt fiber is higher than the tensile strength of the untreated basalt fiber; this behavior may be due to flaw healing effect on the defected fiber surfaces. The IFSS results on the composites confirm that the interaction between the fiber modified with coupling agents and the bio-based epoxy resin was much stronger than that with the untreated basalt fiber.

Keywords: A. Fibres; A. Resins; B. Interface/interphase; B. Stress transfer

\section{Introduction}

The structural integrity and lifetime of polymer composites are critically dependent on the stability of the fiber-matrix interface region [1-3]. Therefore, it is extremely important to characterize the fibre-matrix interface to understand the overall performance of polymer matrix composites. Several micromechanical techniques have been proposed for measuring the interfacial shear strength in fiber-reinforced composites with thermoplastic and thermosetting resins. Some of the most frequently used techniques include the single fiber pull out test [4-6], the single fiber fragmentation test (SFFT) [2, 7-9], the microindentation method, etc.

The SFFT consists of a tensile test of a single fiber originally embedded in a liquid thermoset resin with a particular sample geometry. Then, the system is fully cured under appropriate temperature and time conditions; after this, the composite is subjected to a tensile test and, if the sample is properly designed, the fiber will break progressively into a large number of fragments until fiber break saturation occurs. The final fragment length is called the critical length $\left(l_{c}\right)[9,10]$. This method is attractive because it provides an unambiguous evaluation of the isolated interface, without the complications of a full scale composite assembly, and it requires only a small amount of material, an advantage to those who are screening numerous fiber surface modifications. Although there is unresolved controversy in the literature regarding the use of the SFFT for engineering 
design data, such as interfacial shear strength [9], there is no controversy regarding the use of the test for comparison of different physicochemical interfaces in a given fibermatrix system.

The SFFT method can provide abundant statistical information, e.g., the interfacial failure mode and the SFFT value by using only a few specimens. On the basis of the force balance in a micromechanical model, Kelly and Tyson [11] showed that the interfacial shear strength (IFSS), $\tau$ is given by,

$$
\tau=\frac{\sigma_{f} \cdot d}{2 l_{c}}
$$

Where $d$ is the fiber diameter, $\sigma_{f}$ is the fiber fracture stress, and $l_{c}$ is the critical fragment length.

In recent years there has been a growing interest in the development of thermosetting resins derived from renewable resources such as epoxidized vegetable oils [12-15], which are very attractive for the industry as they can provide similar properties to traditional petroleum-based epoxy resins. In addition, a growing interest on the use of alternative reinforcement fibers to glass has been detected. In particular it is important to remark the growing use of basalt fibers, which may be used alone [16, 17] or in combination with other fibers [18]. It is important to note the growing interest on the use of natural fibers such as hemp [19, 20], flax [21] and jute [22] as reinforcements in polymer composites but the main drawback of these fibers is their sensitiveness to water uptake and their relatively low mechanical properties.

The main aim of this work was to determine the usefulness of different silane coupling agents (with amino and glycidyl functionalities) to improve fiber-matrix interactions between basalt fibers and epoxy resins derived from renewable resources (epoxidized linseed oil-ELO and epoxidized soybean oil-ESBO) because these composite materials have attracted a great deal of attention in recent years [21, 23-26]. Single fiber 
fragmentation test (SFFT) was used to compare the effects of different silane-based coupling agents on basalt-EVO composite systems and also different microscopic techniques were used to validate results. In addition, interfacial shear strength (IFSS) was calculated by Kelly-Tyson approach to quantify the effectiveness of the different silane functionalities.

\section{Experimental}

\subsection{Materials}

Different epoxy resins derived from renewable resources were used as base materials for composites with basalt fibers. Commercial grades of epoxidized linseed oil (ELO) with an EEW (equivalent epoxide weight) of 178 g equiv $^{-1}$ and epoxidized soybean oil (ESBO) with an EEW of 238 g equiv $^{-1}$ were supplied by Traquisa S.A. (Madrid, Spain). As a cross-linking agent, liquid methyl nadic anhydride (MNA) with an EAW (equivalent anhydride weight) of 178.2 g equiv $^{-1}$ supplied by Sigma-Aldrich (Schnelldorf, Germany) was used. Food grade propanediol (PDO) supplied by Coralim Aditivos (Ribaroja del Turia, Spain) was used to provide hydroxyl groups to start the crosslinking reactions, and finally, 1-methyl imidazole (1MI) supplied by Sigma-Aldrich (Schnelldorf, Germany) was used as catalyst/accelerator.

Basalt fibers were supplied by Basaltex (Wevelgem, Belgium) with silane sizing and a nominal diameter of $17 \mu \mathrm{m}$.

Four silanes (two amino- and two glycidyl-silanes) as listed in Table 1 were obtained from Sigma Aldrich. The chemical structure of the different silanes can be observed in Fig. 1.

Table 1 


\section{Figure 1}

\subsection{Silane treatment of basalt fibers}

Before the silane treatment, basalt fibers were heated in a muffle furnace at 350 ${ }^{\circ} \mathrm{C}$ during $2 \mathrm{~h}$ to remove previous sizings used for fiber manufacturing (e.g., binders, coupling agents, etc.) as all these are organic compounds and can be removed at this temperature.

The solutions containing silanes were prepared as follows: 1 wt. \% of silane was diluted in a water-acetone (50-50 volume ratio) solution and the basalt fibers were immersed in these solutions for 1 hour and then the basalt fibers were dried at room temperature for 24 hours.

To verify that the different silane treatments were effective the surface fibers were observed using Field Emission Scanning Electron Microscopy (FESEM, ZEISS ULTRA55, Oxford instruments) at an acceleration voltage of $1 \mathrm{kV}$.

\subsection{Sample preparation for single fiber fragmentation test.}

Liquid resins for casting were prepared with an AEW:EEW ratio of 0.9 for both MNA:ELO and MNA:ESBO systems. 1 wt. \% propanediol and 2 wt. \% 1-methyl imidazole (with regard to the MNA:ELO and MNA:ESBO total weight) were added and all components were mixed to homogenize.

Samples for single fiber fragmentation tests were prepared in a polytetrafluorethylene (PTFE) mold designed with several cavities to place individual fibers. First the individual fibers were placed in the mold and properly centered in the cavities and fixed with adhesive at the ends. Then the liquid resin based on ELO and 
ESBO was casted into the mold and finally the mold was placed in an oven to crosslink the liquid resin. In particular, the ELO:MNA system was subjected to a curing process at $100{ }^{\circ} \mathrm{C}$ during 3 hours while the ESBO:MNA system was cured at $105^{\circ} \mathrm{C}$ during 3.5 hours to obtain a fully cured material.

\subsection{Determination of Weibull parameters and interfacial shear strength}

The single fiber fragmentation test was carried out using a universal tensile tester (Lloyd Instrument, model LR 30K) (Lloyd Instruments Ltd, Bognor Regis, West Sussex UK) with a load cell of $30 \mathrm{kN}$ and at a cross-head speed of $1 \mathrm{~mm} \mathrm{~min}^{-1}$. Images of the samples were captured by an optical microscope Hund H600 (Helmut Hund GmbH, Wetzlar, Germany) and the measurements of embedded lengths were carried out directly on digitized pictures.

The general principle of measuring IFSS is straightforward. Due to the applied force the continuous fiber is progressively broken into short fragments until the fragment length becomes too short to break as shown in Fig. 2. The critical fiber length is defined as the shortest fragment length that breaks due to the applied stress [9, 27]. The following equation can be used to determine the critical length of fibers $[9,10]$.

$$
l_{c}=\frac{4}{3} l_{0}
$$

\section{Figure 2}

The classical relationship among fiber tensile strength, fragment length to diameter ratio and the IFFS, $\tau$ was given by Kelly-Tyson [11]. Widely-distributed $\tau$ values are obtained as a result of random distribution and heterogeneities of flaws in the fibers. The data for both fragment length and fiber strength may be approximated by Weibull 
distribution and these distributions can be combined to calculate the IFSS. Weibull distribution function for two parameters can be written in a more simple form as,

$$
F(l)=\exp \left[-\left(\frac{l}{l_{0}}\right)^{\alpha}\right]
$$

Where $F(l)$ is the probability of survival of the fiber to the length $l, l_{0}$ is the scale parameter, $\alpha$ is the shape parameter (or Weibull modulus) in the Weibull distribution for the aspect ratio. The mean value, $F$, is an estimated probability,

$$
F=\frac{i}{N+1}
$$

Where $N$ is the total number of fiber fragments, and $i$ is the recording number. In order to evaluate the parameters $l_{0}$ and $\alpha$, Eq. (3) can be rearranged into a linearized form as,

$$
\operatorname{Ln}[-\operatorname{Ln}(F(l))]=\alpha \operatorname{Ln}(l)-\alpha \operatorname{Ln}\left(l_{0}\right)
$$

Thus, a plot of $\operatorname{Ln}[-\operatorname{Ln}(F(l))]$ versus $\operatorname{Ln}$ (aspect ratio) yields a straight line whose slope is $\alpha$ and the intercept yields $M$. The scale parameter $l_{0}$ is calculated as,

$$
l_{0}=\exp \left(\frac{M}{\alpha}\right)
$$

Finally, the interfacial shear strength (IFSS) can be estimated by Eq. (1) and Eq. (2) as,

$$
I F S S=\tau=\frac{3}{8} \frac{\sigma_{f} d}{l_{0}}
$$

\subsection{Determination of the tensile strength of fiber}

Tensile strength measurements of basalt fibers were performed at a fixed length of $20 \mathrm{~mm}$. The strength of the fiber was measured using the same universal tensile tester reported before (Lloyd Instrument, model LR 30K) with a load cell of $20 \mathrm{~N}$ and at crosshead speed of $1 \mathrm{~mm} \mathrm{~min}^{-1}$. Weibull statistics were applied to analyze the fibers strength.

\section{Results and discussion}




\subsection{Analysis of basalt fiber}

Basalt fibers are brittle and susceptible to deteriorate (reduction of the tensile strength) due to surface oxidation and defects. For this reason and due to the basalt fiber production process, fibers don't have a uniform diameter throughout their length and this leads to a broad tensile strength distribution which is suitable to be analyzed with the Weibull distribution. Table 2 shows the fiber tensile strength of the untreated basalt fiber and of the basalt fibers treated with different silanes. As we can see, silane-treated basalt fibers show higher tensile strength than the untreated fiber (1487 $\mathrm{MPa})$, and maximum values of tensile strength are obtained with the amino-silane B (basalt_B) with values around $1651 \mathrm{MPa}$. Also we can see there is a concentration in the dispersion of the results for silane-treated basalt fibers. These results indicate a flaw healing and/or stabilization effect of the silanes on the defected fiber surfaces [28].

\section{Table 2}

Fig. 3 shows FESEM images of basalt fibers with different silane treatment. For untreated (only heated up to $350{ }^{\circ} \mathrm{C}$ to remove previous organic sizing) basalt fiber, the surface is relatively smooth and clean. Silane treatment promotes formation of a thin silane layer which can be strongly attached to basalt surface through reaction between the hydrolyzed alkoxy groups in the silane and hydroxyl functional groups in basalt surface. On the other hand, the amino or glycidyl functionality is still active and can react with the epoxy resin thus leading to good interaction among fiber-matrix. The surface of the silane-treated basalt fibers (Fig. 3 b, c, d and e) is characterized by a rougher surface (if compared to untreated basalt fiber) due to the anchorage of silane coupling agents which will play a key role in establishing strong interactions among fiber and matrix. As it can 
be seen in Fig. 3b, corresponding to the silane treatment with amine functionality, it appears that this is the worst treatment performed because the silane coating is the poorest since, apparently, it is characterized by low surface roughness. In addition, as discussed below, basalt fibers with this treatment offer low interaction with the epoxy resins.

\section{Figure 3}

\subsection{Interfacial shear strength (IFSS) in ELO and ESO composites with basalt fiber}

The fragment lengths embedded in samples became smaller with increasing strain, since matrix around long-broken fiber still transfer stress to the basalt fiber. Fig. 4 shows the Weibull distribution of theoretical and experimental data obtained from two samples, ELO:MNA with untreated basalt fiber (ELO_basalt) and ELO:MNA with a glycidyl silane (ELO_basalt_D). For both materials it can be observed that the experimental data are consistent with the theoretical Weibull distribution; we can also observe that the fracture lengths of the silane-treated basalt fiber (ELO_basalt_D) are always smaller than the fracture length for ELO:MNA system with untreated basalt fiber.

\section{Figure 4}

Table 3 shows the Weibull distribution parameters and the corresponding IFSS (as calculated by eq. 7) for composites based on ELO:MNA and ESBO:MNA systems with basalt fibers with different silane treatments. We can see that IFSS is inversely related to scale parameter $l_{0}$ so that, the smaller the $l_{0}$, the higher the IFSS becomes.

Table 3 
IFSS improves when the basalt fiber is treated with silanes in all cases. It is important to remark that the highest IFSS value is obtained when the basalt fiber is treated with the silane C (glycidyl silane); España J.L. et.al. manufactured different composites with a biobased epoxy resin (Greenpoxy 55) and basalt fabrics modified with silanes and the material with higher tensile modulus was the glycidyl silane modified fabric as in this study [29]. In addition ELO composites with basalt fibers are characterized by higher IFSS value than ESBO-based composite systems.

Such high improvements can be due to chemical and/or physical bonding among the fiber-matrix interface in composite systems. The silane acts as a coupling agent between the inorganic component (basalt fiber) and the organic component (epoxy resin). As we have described previously, previous hydrolysis of silane in water-acetone solution enables hydrolysis of alkoxy groups (methoxy groups in this study) thus forming hydroxyl groups in silane molecules (silanol) that can react with hydroxyl groups in basalt fiber thus leading to silane attachment into basalt fiber surface. Also, reactions between hydroxyl groups of different silane molecules can occur and this leads to formation of a siloxane (Si-O-Si). All these processes lead to strong attachment between the silane coupling agent and the inorganic component. On the other hand, in addition to the alkoxy groups (that lead to coupling with inorganic component), silane is provided by an organic functional group, amino and glycidyl, that are suitable to react with the organic component of the composite (in this case, an epoxy resin). Amino groups in silane_A and silane_B can react with oxirane rings in the biobased epoxy resin thus leading to crosslink of epoxy resin with silane (Fig. 5). In this case, the amino functionality present in the silane coupling agent acts as crosslinker together with the cyclic anhydride [28]. On the other hand, the reaction of glycidyl silane is as follows: in a first stage, the cyclic 
anhydride reacts with hydroxyl groups to open the cyclic anhydride thus leading to formation of a free carboxylic acid group (Fig. 6[a]) with new hydroxyl groups which can further react with more cyclic anhydride rings to form new carboxylic groups. These carboxylic groups can react with oxirane rings in the epoxy resin and glycidyl silane coupled to basalt fiber to crosslink the structure (Fig. 6[b]) [30].

\section{Figure 5}

\section{Figure 6}

Fig. 7 shows an optical photograph of a fractured fiber sample for (a) untreated basalt-ELO:MNA sample, and (b) basalt_C- ELO:MNA. In Fig.7(b), fiber fragment lengths treated with silane_C are shown to be relatively shorter than the untreated case (Fig. 7 [a]), which means higher IFSS due to previous Kelly and Tyson Eq. (1). In addition, many numbers of the fiber fracture are based on the better stress transfer from matrix to fiber.

\section{Figure 7}

\section{Conclusions}

Interfacial shear strength (IFSS) using silane coupling agent for basalt fibers reinforced biobased epoxy resin, epoxidized linseed oil (ELO) and ESBO epoxidized soybean oil (ESBO), were investigated via fragmentation test. Silane treated basalt fibers showed higher fiber strength than those of the optimum untreated owing to healing and stabilization effect of surface flaws. 
The results of IFSS verified that the interaction between the fiber modified with coupling agent and biobased epoxy resin was much stronger than the untreated fiber/biobased epoxy. The basalt fiber modified with glycidyl-silanes showed the best improvement in interfacial adhesion. The results indicate that trimethoxy[2-(7oxabicyclo[4.1.0]hept-3-yl)ethyl] silane could be used as a good coupling agent for the basalt/ELO and basalt/ESBO systems.

\section{ACKNOWLEDGEMENTS}

The authors acknowledge the support received from the Programme Support Research and Development (PAID-00-12) of the Polytechnic University of Valencia to carry out a research stay in foreign centres. 


\section{REFERENCES}

[1] Lopattananon N, Kettle AP, Tripathi D, Beck AJ, Duval E, France RM, et al. Interface molecular engineering of carbon-fiber composites. Compos Pt A-Appl Sci Manuf. 1999;30(1):49-57.

[2] Nishikawa M, Okabe T, Takeda N. Determination of interface properties from experiments on the fragmentation process in single-fiber composites. Mater Sci Eng AStruct Mater Prop Microstruct Process. 2008;480(1-2):549-57.

[3] Rao V, Herrerafranco P, Ozzello AD, Drzal LT. A direct comparison of the fragmentation test and the microbond pull-out test for determining the interfacial shearstrength J Adhes. 1991;34(1-4):65-77.

[4] Doan TTL, Brodowsky H, Mader E. Jute fibre/epoxy composites: Surface properties and interfacial adhesion. Compos Sci Technol. 2012;72(10):1160-6.

[5] Kim Y. Tensile Properties of Carbon-Glass/Epoxy Hybrid Laminates Produced by VARTM. Korean J Met Mater. 2011;49(10):760-5.

[6] Koyanagi J, Nakatani H, Ogihara S. Comparison of glass-epoxy interface strengths examined by cruciform specimen and single-fiber pull-out tests under combined stress state. Compos Pt A-Appl Sci Manuf. 2012;43(11):1819-27.

[7] Johnson AC, Hayes SA, Jones FR. The role of matrix cracks and fibre/matrix debonding on the stress transfer between fibre and matrix in a single fibre fragmentation test. Compos Pt A-Appl Sci Manuf. 2012;43(1):65-72.

[8] Pupurs A, Goutianos S, Brondsted P, Varna J. Interface debond crack growth in tension-tension cyclic loading of single fiber polymer composites. Compos Pt A-Appl Sci Manuf. 2013;44:86-94.

[9] Tripathi D, Jones FR. Single fibre fragmentation test for assessing adhesion in fibre reinforced composites. J Mater Sci. 1998;33(1):1-16. 
[10] Awal A, Cescutti G, Ghosh SB, Mussig J. Interfacial studies of natural fibre/polypropylene composites using single fibre fragmentation test (SFFT). Compos Pt A-Appl Sci Manuf. 2011;42(1):50-6.

[11] Kelly A, Tyson WR. Tensile properties of fiber-reinforced metals - copper/tungsten and copper/molybdenum. J Mech Phys Solids. 1965;13(6):329-\&.

[12] Altuna FI, Esposito LH, Ruseckaite RA, Stefani PM. Thermal and Mechanical Properties of Anhydride-Cured Epoxy Resins with Different Contents of Biobased Epoxidized Soybean Oil. J Appl Polym Sci. 2011;120(2):789-98.

[13] Harry-O'kuru RE, Mohamed A, Gordon SH, Xu J. Syntheses of Novel Protein Products (Milkglyde, Saliglyde, and Soyglyde) from Vegetable Epoxy Oils and Gliadin. J Agric Food Chem. 2012;60(7):1688-94.

[14] Pan X, Sengupta P, Webster DC. High Biobased Content Epoxy-Anhydride Thermosets from Epoxidized Sucrose Esters of Fatty Acids. Biomacromolecules. 2011;12(6):2416-28.

[15] Stemmelen M, Pessel F, Lapinte V, Caillol S, Habas JP, Robin JJ. A Fully Biobased Epoxy Resin from Vegetable Oils: From the Synthesis of the Precursors by Thiol-ene Reaction to the Study of the Final Material. J Polym Sci Pol Chem. 2011;49(11):243444.

[16] Kim H. Thermal Characteristics of Basalt Fiber Reinforced Epoxy-Benzoxazine Composites. Fiber Polym. 2012;13(6):762-8.

[17] Wang HS, Wang GB, Zhang LM, Jiang ZH, Guan SW, Zhang SL. Influence of the addition of lubricant on the properties of poly(ether ether ketone)/basalt fiber composites. High Perform Polym. 2012;24(6):503-6. 
[18] Dehkordi MT, Nosraty H, Shokrieh MM, Minak G, Ghelli D. The influence of hybridization on impact damage behavior and residual compression strength of intraply basalt/nylon hybrid composites. Mater Des. 2013;43:283-90.

[19] Guillebaud-Bonnafous C, Vasconcellos D, Touchard F, Chocinski-Arnault L. Experimental and numerical investigation of the interface between epoxy matrix and hemp yarn. Compos Pt A-Appl Sci Manuf. 2012;43(11):2046-58.

[20] Pickering KL, Sawpan MA, Jayaraman J, Fernyhough A. Influence of loading rate, alkali fibre treatment and crystallinity on fracture toughness of random short hemp fibre reinforced polylactide bio-composites. Compos Pt A-Appl Sci Manuf. 2011;42(9):114856.

[21] Charlet K, Jernot JP, Gomina M, Bizet L, Breard J. Mechanical Properties of Flax Fibers and of the Derived Unidirectional Composites. J Compos Mater. 2010;44(24):2887-96.

[22] Barreto ACH, Esmeraldo MA, Rosa DS, Fechine PBA, Mazzetto SE. Cardanol Biocomposites Reinforced with Jute Fiber: Microstructure, Biodegradability, and Mechanical Properties. Polym Compos. 2010;31(11):1928-37.

[23] Bledzki AK, Jaszkiewicz A. Mechanical performance of biocomposites based on PLA and PHBV reinforced with natural fibres - A comparative study to PP. Compos Sci Technol. 2010;70(12):1687-96.

[24] Samper MD, Fombuena V, Boronat T, Garcia-Sanoguera D, Balart R. Thermal and Mechanical Characterization of Epoxy Resins (ELO and ESO) Cured with Anhydrides. J Am Oil Chem Soc. 2012;89(8):1521-8.

[25] Terenzi A, Kenny JM, Barbosa SE. Natural fiber suspensions in thermoplastic polymers. I. Analysis of fiber damage during processing. J Appl Polym Sci. 2007;103(4):2501-6. 
[26] Thakur VK, Singha AS. Physico-chemical and Mechanical Characterization of Natural Fibre Reinforced Polymer Composites. Iran Polym J. 2010;19(1):3-16.

[27] Herrerafranco PJ, Drzal LT. Comparison of methods for the measurement of fibrex matrix adhesion composites. Composites. 1992;23(1):2-27.

[28] Park JM, Shin WG, Yoon DJ. A study of interfacial aspects of epoxy-based composites reinforced with dual basalt and SiC fibres by means of the fragmentation and acoustic emission techniques. Compos Sci Technol. 1999;59(3):355-70.

[29] España JM, Samper MD, Fages E, Sanchez-Nacher L, Balart R. Investigation of the Effect of Different Silane Coupling Agents on Mechanical Performance of Basalt Fiber Composite Laminates with Biobased Epoxy Matrices. Polym Compos. 2013;34(3):37681.

[30] Holmes GA, Feresenbet E, Raghavan D. Using self-assembled monolayer technology to probe the mechanical response of the fiber interphase-matrix interphase interface. Compos Interfaces. 2003;10(6):515-46. 


\section{Figure legends}

Figure 1. Structures of silane coupling agents used for the treatment of the basalt fibers:

(a) (3-aminopropyl)trimethoxysilane),

(b) [3-(2-aminoethylamino)propyl]-

trimethoxyxilane, (c) trimethoxy[3-(7-oxabicyclo[4.1.0]hept-3-yl)ethyl]silane and (d) (3glycidyloxypropyl)trimethoxysilane.

Figure 2. Schematic representation of the evolution of failures during SFFT.

Figure 3. FESEM photographs of basalt fibers (X5000): (a) untreated (only heated to remove previous organic sizing), (b) treated with (3-aminopropyl) trimethoxysilane, (C) treated with [3-(2-aminoethylamino)propyl]-trimethoxyxilane, (d) treated with trimethoxy[3-(7-oxabicyclo[4.1.0]hept-3-yl)ethyl]silane, and (e) (3glycidyloxypropyl)trimethoxysilane.

Figure 4. Weibull plot of single fiber fracture test of ELO:MNA system with untreated basalt fiber and glycidyl (silane_D) treated basalt fiber.

Figure 5. Schematic representation of coupling mechanism of amino-silane (silane A and silane B).

Figure 6. Schematic representation of coupling mechanism of glycidyl-silane (silane C and silane D) with epoxy resin. (a) Bonding mechanism between the anhydride and the PDO, forming dicarboxylic acids; (b) bonding mechanism between the epoxy resin and the glycidyl silane using the dicarboxylic acid

Figure 7. Optical photograph of single fiber fracture test of (a) untreated basalt fiber ELO:MNA composite; and (b) basalt_C-ELO:MNA composite. 
Table 1. Silanes used to improve fiber-matrix interactions and nomenclature of samples.

\begin{tabular}{|l|l|l|}
\hline Silane & Silane type & Nomenclature of \\
& & silane-treated basalt \\
fibers
\end{tabular}


Table 2. Tensile strength of untreated and silane-treated basalt fibers analyzed by Weibull distribution.

\begin{tabular}{|l|c|c|c|}
\hline \multirow{2}{*}{ Fiber } & $\begin{array}{c}\text { Number of } \\
\text { samples }\end{array}$ & $\begin{array}{c}\text { Tensile } \\
\text { strength (MPa) }\end{array}$ & $\begin{array}{c}\text { Shape parameter } \\
(\boldsymbol{\alpha})\end{array}$ \\
\hline Untreated basalt & 22 & $1487(492)^{*}$ & 2.89 \\
\hline Basalt_A & 22 & $1572(329)$ & 4.55 \\
\hline Basalt_B & 20 & $1651(464)$ & 5.05 \\
\hline Basalt_C & 19 & $1499(240)$ & 4.59 \\
\hline Basalt_D & 21 & $1523(325)$ & \\
\hline
\end{tabular}

*Values between parentheses correspond to the standard deviation 
Table 3. Interfacial shear strength (IFSS) and Weibull distribution parameters for ELO:MNA and ESBO:MNA systems with basalt fibers with different silane treatments.

\begin{tabular}{|c|c|c|c|}
\hline Sample & Scale parameter $\left(\mathrm{l}_{0}\right)$ & $\begin{array}{c}\text { Shape } \\
\text { parameter }(\alpha)\end{array}$ & IFSS (MPa) \\
\hline ELO_Basalt & 1249 (302) & 4.31 & 7.6 \\
\hline ELO_Basalt_A & 1173 (339) & 3.71 & 8.5 \\
\hline ELO_Basalt_B & 1054 (266) & 4.01 & 10.0 \\
\hline ELO_Basalt_C & 805 (146) & 5.67 & 11.9 \\
\hline ELO_Basalt_D & $862(183)$ & 4.78 & 11.3 \\
\hline ESBO_Basalt & 1533 (339) & 4.81 & 6.2 \\
\hline ESBO_Basalt_A & 1178 (229) & 5.16 & 8.5 \\
\hline ESBO_Basalt_B & $1134(238)$ & 5.01 & 9.3 \\
\hline ESBO_Basalt_C & 917 (199) & 4.84 & 10.4 \\
\hline ESBO_Basalt_D & $1104(211)$ & 5.35 & 8.8 \\
\hline
\end{tabular}

*Values between parentheses correspond to the standard deviation 
Figure 1<smiles>CO[Si](CCCN)(OC)OC</smiles>

a)<smiles>CO[Si](CCC1CCC2OC2C1)(OC)OC</smiles><smiles>CO[Si](CCCNCCN)(OC)OC</smiles><smiles>CO[Si](CCCOCC1CO1)(OC)OC</smiles> 
Figure 2

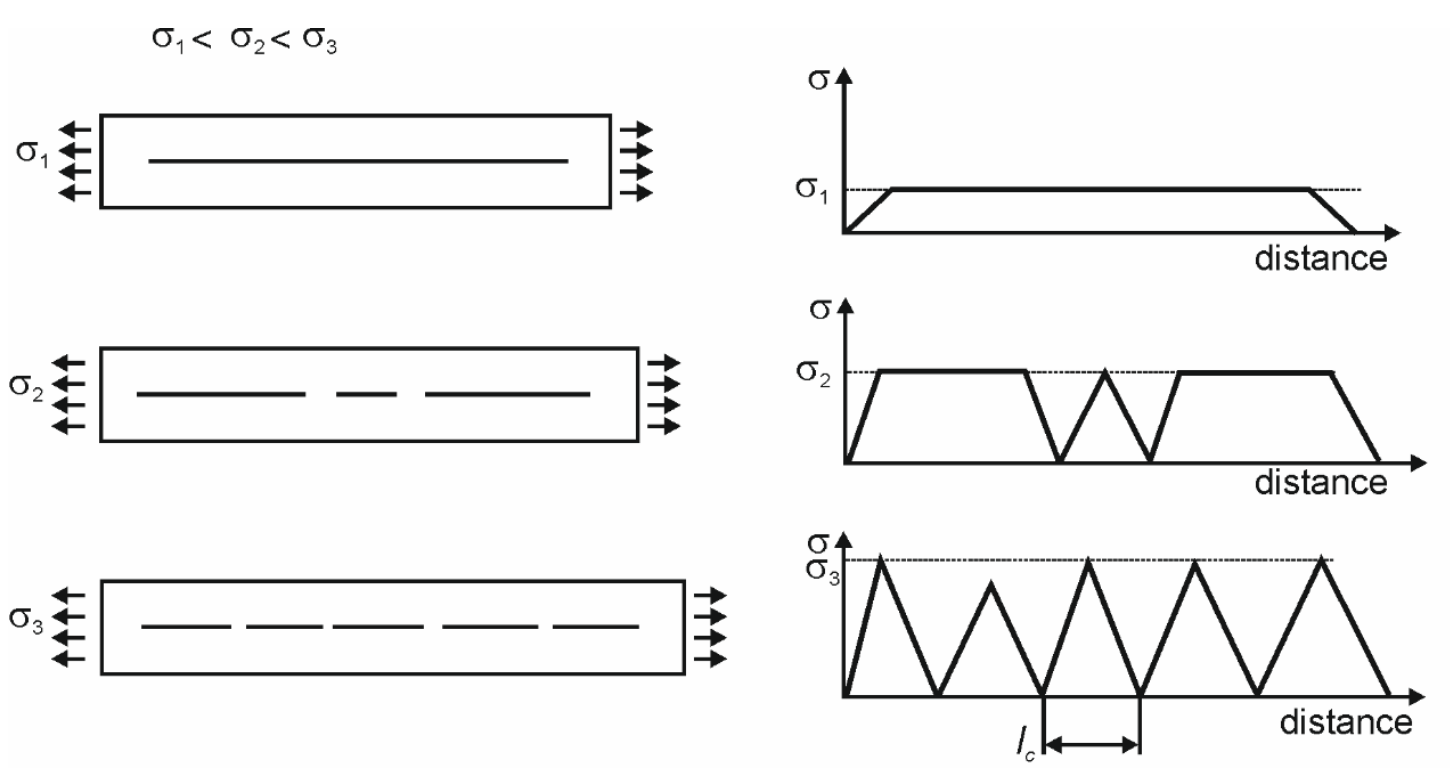


Figure 3

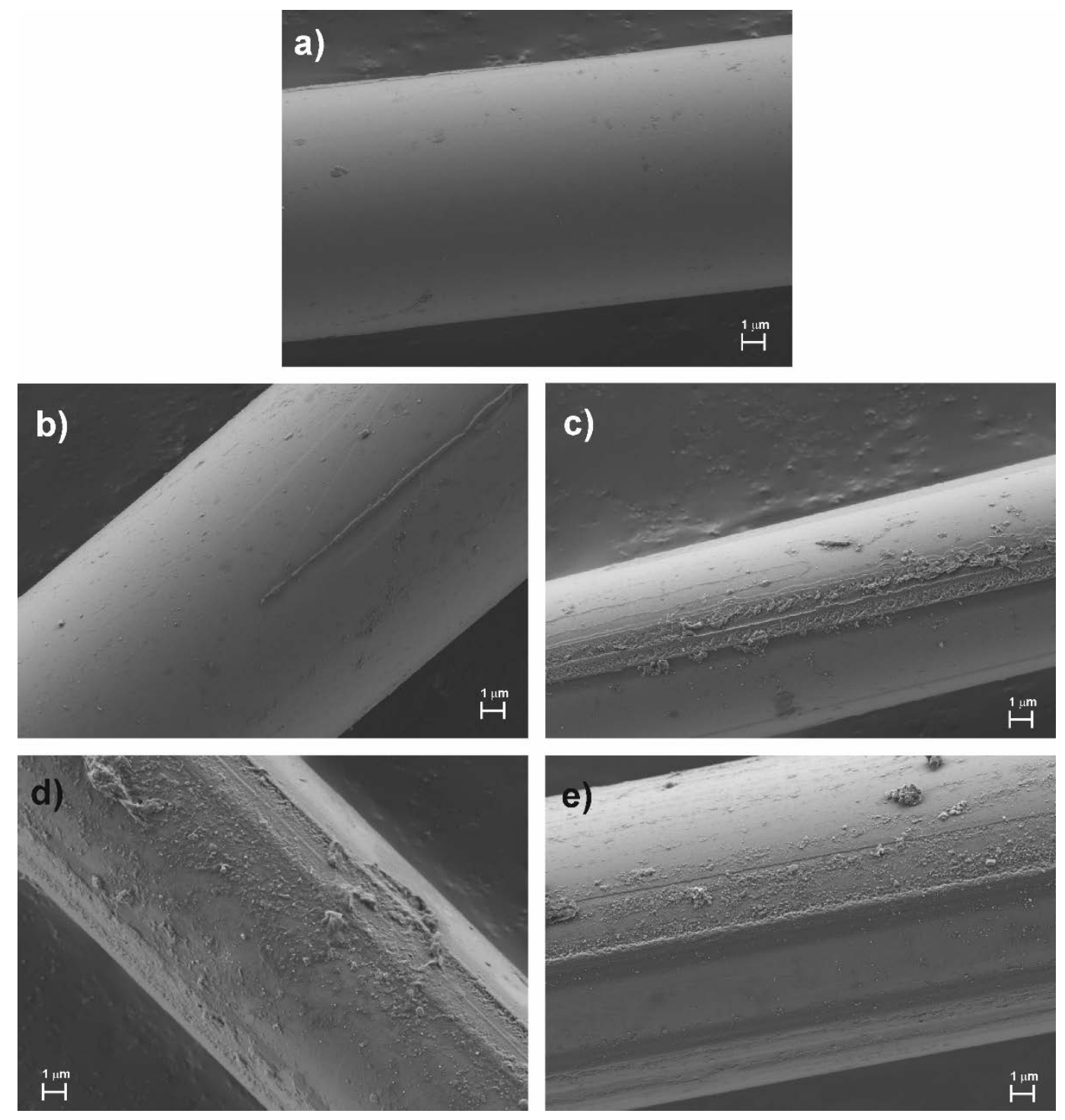


Figure 4

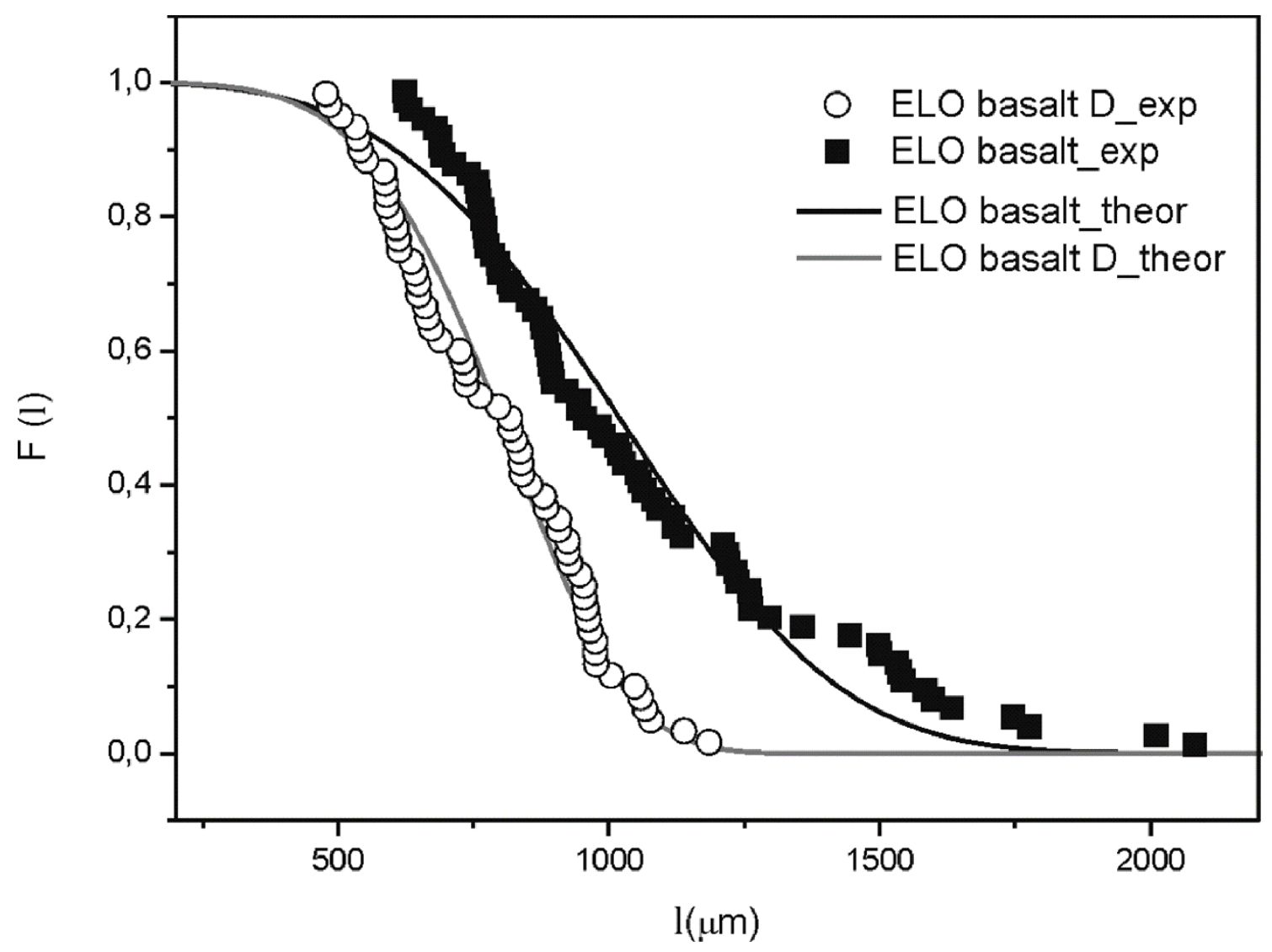


Figure 5
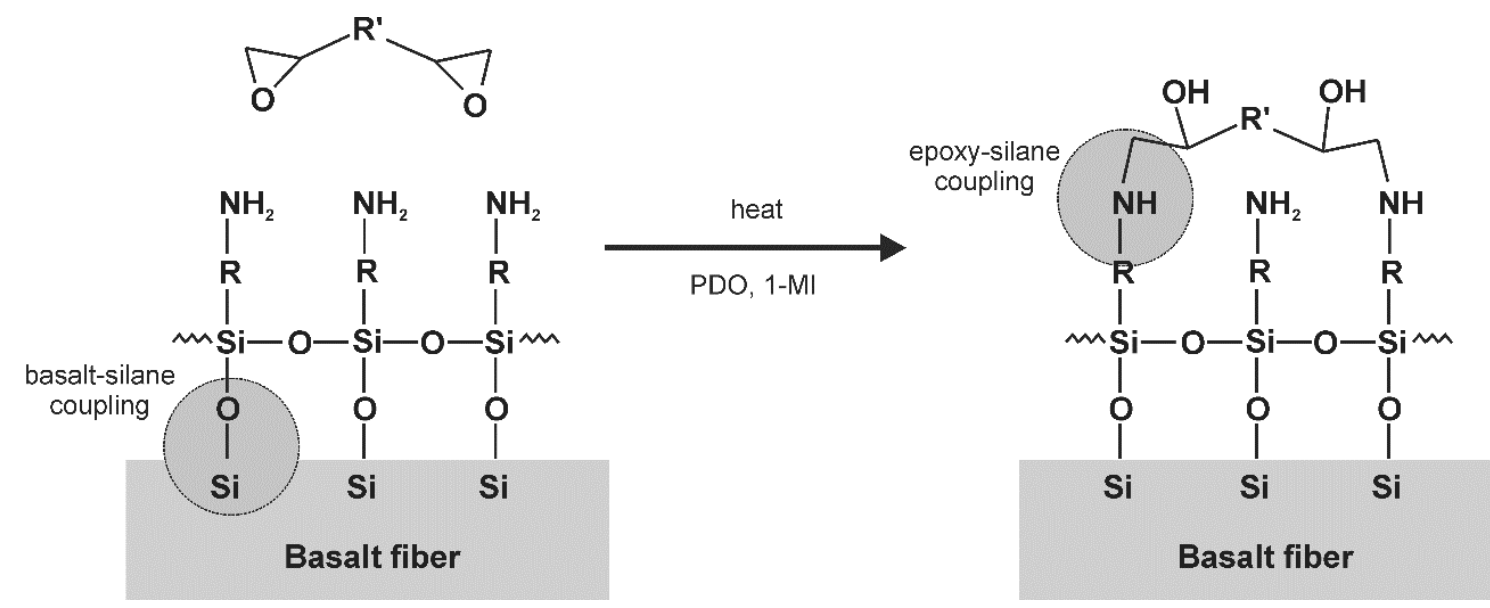
Figure 6

a)

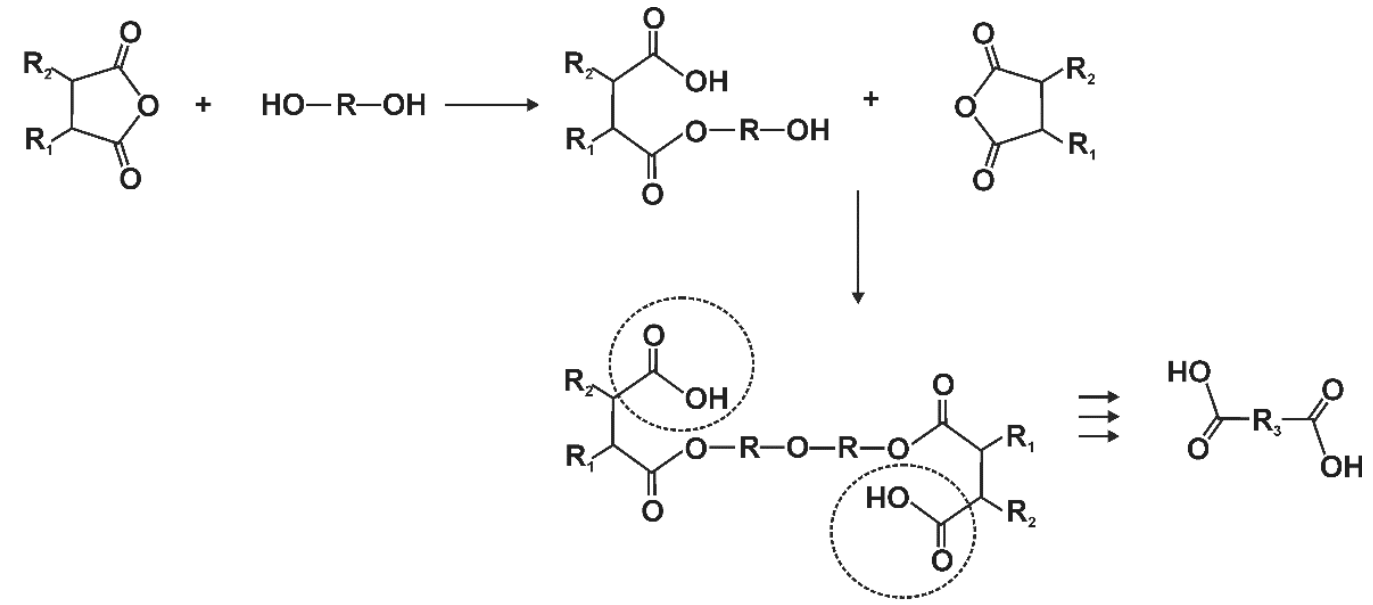

b)
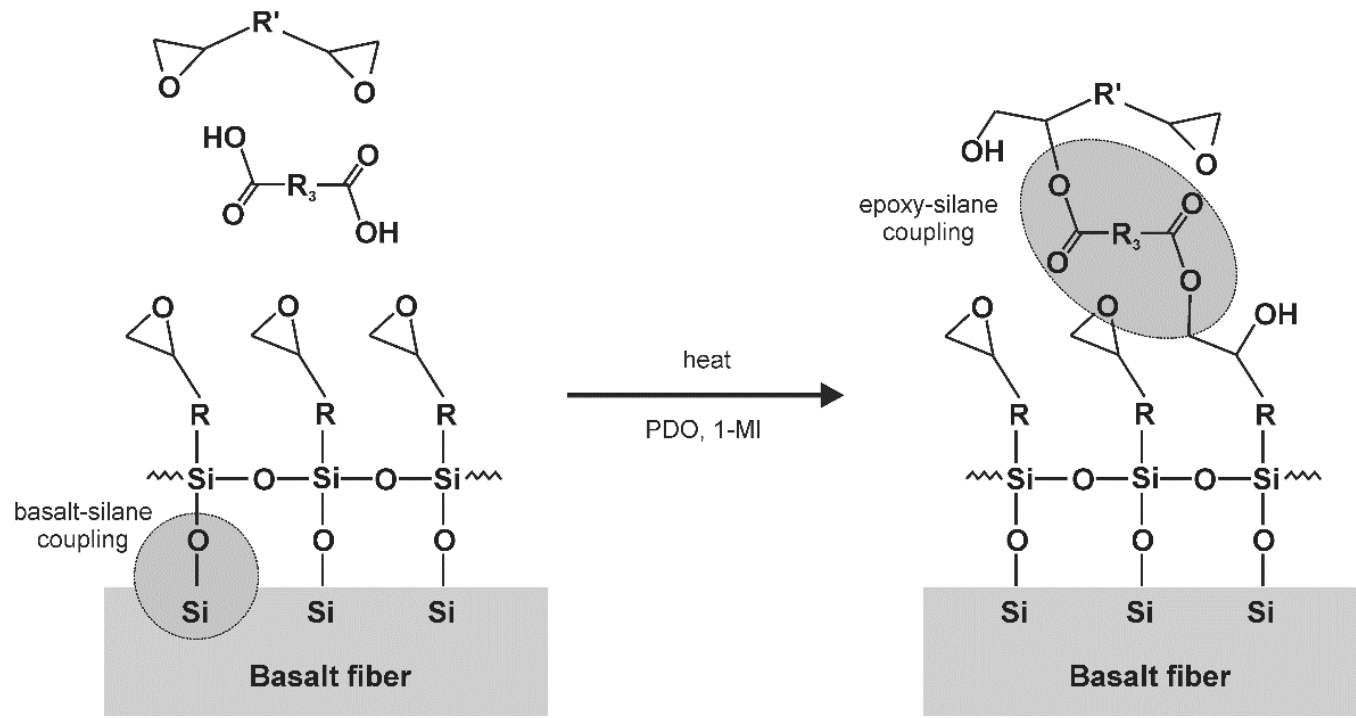
Figure 7

a)

$0.2 \mathrm{~mm}$

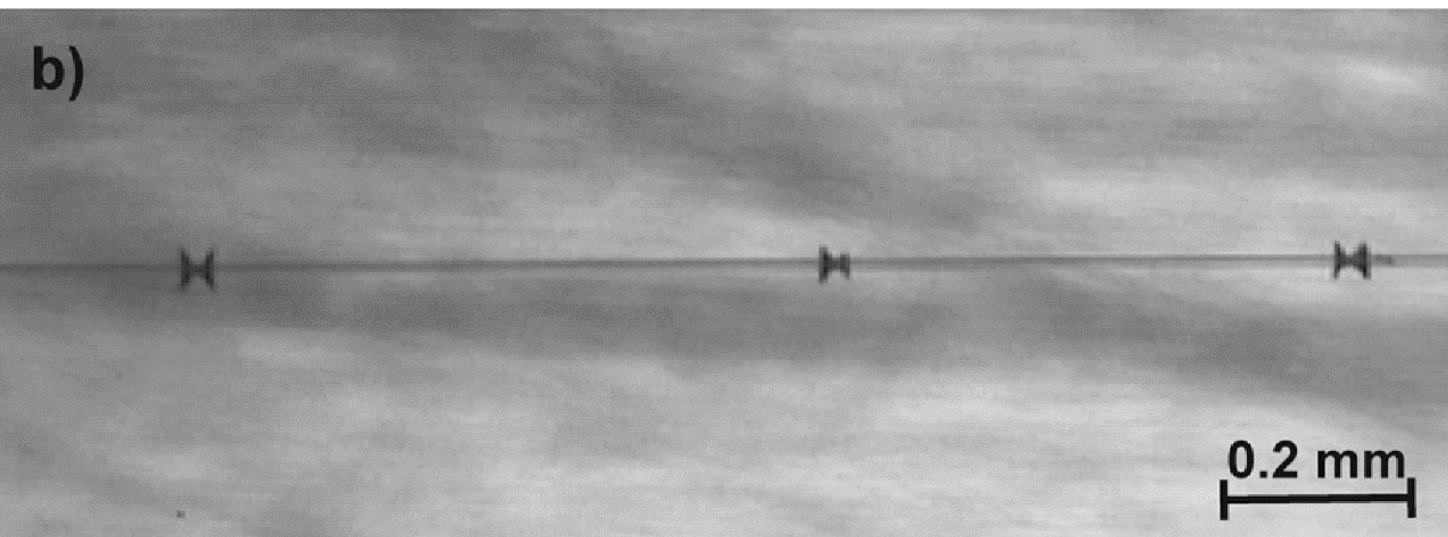

